Cited as: Tavares, N., Chu, S.K.W. \& Weng, M. (2011). Experimenting with English Collaborative Writing on Google Sites. Paper presented at CITE Research Symposium 2011, The University of Hong Kong, Hong Kong.

\title{
Experimenting with English Collaborative Writing on Google Sites
}

\author{
Nicole Tavares, Chu, Samuel Kai Wah and Muriel Weng
}

\begin{abstract}
:
A considerable amount of research has shown the advantages of integrating Web 2.0 technologies with language teaching to students. Specifically, this paper will shed light on the positive effects of Google Sites in teaching and learning English after the pilot scheme of online collaborative writing on Google Sites implemented by four local primary schools, revealed by the qualitative data such as samples of students' and teachers' revisions and comments, as well as the result of the focus group interviews. Both students' and teachers' revisions and comments reveal that most of the advantages of using Google Sites accord with those suggested by previous research studies. Some concerns will also be raised to offer insights into a serious attempt to integrate Web 2.0 and teaching language under the context of Hong Kong in the future.
\end{abstract}

Keywords: Collaborative learning, English writing, primary schools, Google Sites, Wikis, Hong Kong

\section{Introduction}

Writing in English has always been a challenge to many local students in primary schools. Acknowledging the fruitful results of using web-based collaborative tools in conducting projects across different subjects (Woo, Chu, Ho \& Li, 2011), the study of Experimenting with English Collaborative Writing on Google Sites aims to examine the extent to which collaborative learning in a Web 2.0 environment can enhance students' writing performance. Web 2.0 technologies have been chosen to be the tools used in this study because they provide a free online collaborative platform for students to co-construct their group projects with the teacher's facilitation, enabling timely feedback, monitoring of their work and appropriate interventions.

\section{Literature Review}

New technologies have had a tremendous impact on the teaching and learning of English writing in the last few decades (Goldberg, Russell, \& Cook, 2003). Many studies have started to appear on the application of Web 2.0 in education involving collaborative tools called wikis (Woo, Chu, Ho \& Li, 2011, p. 43). Google Sites is a kind of wiki which is a "collaborative web space where anyone can add content and anyone can edit content that has already been published" (Richardson, 2006, p.8). Hossain \& Aydin (2011) suggested that social networking applications such as blogs, forums, podcasts, and wikis are the successful implementations of the new generation Web 2.0 technologies (p. 116) which enable users to develop a collaborative virtual society to share information interactively and interoperably (p.118).

A considerably amount of studies in the past decade has pointed out the benefits of Google Sites and other similar wikis. First of all, it can promote social and achievement motivation. Alexander (2006) suggested that the interactive and read-write natures of Web 2.0 technologies could facilitate users' participation in and build many rich and user-centered virtual communities that could attract more people to participate and interact in 
building many collaborative societies simultaneously. Also, providing a genuine audience enhances learner motivation, which helps L2 students become more engaged writers (Lo \& Hyland, 2007). Likewise, as cited in Trentin (2009), wikis allow learners to be actively involved in their own knowledge construction (Boulos et al. 2006) and in the co-writing processes (Parker \& Chao, 2007). Obviously, wikis are able to motivate every student to get involved in the writing process and contribute their best in knowledge construction due to social motivation.

Apart from igniting students' motivation to get involved in the writing process, Google Site is also convenient for students to contribute to the project. According to Woo, Chu, Ho \& Li (2011), wikis allows students to work at their own pace. Hossain \& Aydin (2011) also suggested that wikis allow users to have different levels of access to edit or delete content. Students can contribute according to their availability as well as their ability.

Moreover, Google Site is easy for students to use. Creating or editing a wiki requires only basic computing knowledge - no programming knowledge at all. So primary school students nowadays who are digital natives should find wikis like Google Sites not difficult to learn. According to Nicol, Littlejohn \& Grierson (2005), the easy accessibility, simplicity and transparency of wiki pages helps learners to share information and resources among their team members and across groups. Wikis has proven to be manageable to the generation of digital natives.

The topics of the collaborative writing can be more personal, such as inviting students to write one of the aspects of their secondary school life (Sze 2010), or content-based like three instructional sciences themes: behaviorism, cognitivism, and constructivism (Zhu, Valcke \& Schellens, 2009) so that all students regardless of ability can contribute to the project.

Woo, Chu, Ho, \& Li (2009) did a similar study to explore the challenges and potential benefits that a wiki may bring to students and teachers in a Primary five English class. The result showed that the students held a positive attitude towards the process and the product of the collaborative writing. A more recent study by Woo, Chu, Ho, \& Li (2011) has reconfirmed that students enjoyed using the wiki and the overall perception was that it helped foster teamwork and improve writing. Although a few studies have shed a positive light in the area of using technologies such as wikis to compose and revise text with primary school children, the number of articles which discussed specifically the effects of Google Sites or wikis in teaching English writing in primary school is still very limited. So far, no research has been found to involve several schools as a whole in the investigation under the Hong Kong context. Whether or not Google Sites are applicable to most of young learners at the primary school level in Hong Kong needs further investigation. This study aims to address these gaps, by describing the effect of using Google Sites for collaborative English writing online as well as the, with the example of four local primary schools in Hong Kong.

\section{Research Method \\ 3.1 Participants}

Four local primary schools including FK, HS, SP and KS were invited to participate in this project so as to ensure a sufficient quantity of writings could be produced to examine the effect of online collaborative writing. Students were asked to do a collaborative writing on paper in the first term, then to do writing on wiki in the second term so as to refine their reading and writing skills. The four schools were different from each other in terms of the number of classes involved, the composition topic and the implementation plan.

FK involved two classes and the topic of writing is Our Weekend Activities. Only group entry with individual writing of all group members is required, for instance, in Appendix A, Gp03 refers to group 3's work. There are also two classes participating in online collaborative writing for HS, but the implementation plan is more complicated with Cheung Chau Bun Festival being the topic. Students from the ten groups need to do a group mind-mapping, presentations and peer evaluation before putting the group script-writing and PowerPoint slides on Google sites. An example can be found in Appendix B.

The topic of SP is Lost while the topic of KSW is Good Person, Good Deeds. But SP has a different approach of implementation which requires individual to write on paper and then post it on Google Sites for group and teacher feedback. All students are ensured to contribute to the Google Sites (see left roll of class number in Appendix C). Four classes are involved in KSW (see Appendix D) with eight to nine groups per class. There are less group members within the group, unlike the other three schools.

\subsection{Intervention Program}

I: $\backslash$ Sam-research\QEF\Publications\Conference paper of CITERS 2011 Experimenting with English collaborative writing (Nicole)\Experimenting with English Collaborative Writing on Google Sites v2.doc 1/26/2010 
There were pre- and while-intervention professional development workshops that the teachers learnt how to conduct process writing. Teachers would then intervene in students' writings in both pen-and-paper format and via Google Sites.

The role of teachers was compromised in the workshop to make sure every teacher understand their responsibilities and their role of a facilitator.

\subsection{Data Collection}

3.3a Focus Group Interviews with Teachers and Students

Focus group interviews were conducted so as to gather students' opinions towards the usage of Google sites to do their writings. In general, most of the teachers and students held a positive attitude towards Google Sites. Some qualitative data will be quoted in the part 4 .

$\underline{3.3 b}$ Documentary Analysis of the Students' progress

Google Site page history is able to reveal information on types of revisions that occurred, allowing a trace of how different peer feedbacks lead to actual revisions, resulting in better group writing as a result. This advantage is the crucial advantage for process writing as it can show the improvement of students during a period. As While \& Ardnt (1991) suggested, process writing is "a complex, cognitive process that requires intellectual effort over a considerable period of time". Qualitative and quantitative data were collected and examined through multiple sources of evidence, including evaluation of students' group writing, students' comments posted on wiki

platform and editing information recorded in the wiki's history page.

\section{Findings and Discussion}

\subsection{Peer Pressure to write}

Shown by Appendix E, peers urge the writer to write something for them to read. "?????????", "Where is you writing?", "Were your writing eaten by yourself?" are some examples of their request to urge the writer write something. Peer monitoring is possible with Google Sites, which is more effective and able to share teachers' workload.

\subsection{Peer Learning}

Students are capable of leaving meaningful comments regarding spelling, grammar, organization and rationality. In many cases, the mistake that is easiest for all students to spot out is spelling mistake (Appendix F). Shown by Appendix G, stronger students can even list out a number of corrections at one time in a comment. Also, average students can comment on the rationality of the story like the following instance emthasizing the

impossibility of Big Buddha in Tai Mo Shan.

writing2 p 5 process $\cdot 2011 / 6 / 20$ 下午 $6: 50$

go to Tai Mo Shan visit the Big Buddha?

Tai Mo Shan have the Big Buddha?

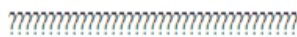

Most importantly, students offer help to each other when some of them have queries. An example is that a peer student said "Your writing is good but I do not the meaning of truthful", the writer then answers "truthful means honest".

The common platform enables mutual appreciation. As quoted by a student in the focus group interview, "If we use Google Sites as the collaborative platform, we read the writings from other classes and comment on our classmates' work in order to exchange views. If we write it on paper, we can just read a few pieces of writings."

\subsection{Teachers' Support}

Teachers were noticed to act as a facilitator throughout the project. Constructive comments like the following example were given by teachers to give guidance to students in how to write better. 


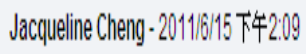

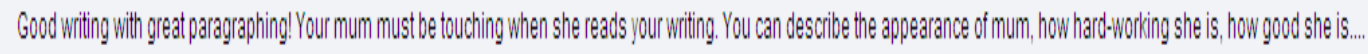

Also, encouragements were seen to be given by teachers to motivate students to strive for their best.

意見 (5)

Cherry KWOK - 2011/3/31 下午3:26

Good introduction (by Miss Kwok)

Miss Cheung - 2011/3/31 下午3:33

Good try ! Keep going !

Miss Cheung - 2011/3/31 下午3:40

I look forward to seeing your story soon. Keep going!

In this example, Miss Kwok and Miss Cheung praised the writer and encourage him to keep writing. All the participating teachers were noticed to be aware of their role as a facilitator and to try their best to drive the students to improve their writing.

\subsection{Benefits of Google Site in itself}

Students were asked about the advantages of Google Sites regarding how it had aided their group project. Out of many advantages, two of them stood out to be the most important in the eyes of students --- the accessibility and the convenience of editing and searching information.

\section{$\underline{4.5 a}$ Accessibility}

S5A: "We can do our work both at home and at school."

S1A: "If we use Google Sites, all group members can do the group project at the same time, unlike Microsoft Word. It is simpler and easier to manage."

S5C: "If you save it, you can log in and access it on any computer. It is more convenient than using paper."

In the eyes of students, Google Sites can be accessed anytime anywhere, which is convenient for them to work as an individual or as a group.

\section{$4.5 \mathrm{~b}$ Convenience of editing and searching information}

S2D: "If we type something wrong, we can simply press the 'delete' button to amend the errors. If we write something wrong on paper, we have to waste correction pen."

S7: "we can check those words we do not know using the dictionary [on Google Sites], and can translate the Chinese words into English ... for those words we do not know."

S1A: "Working online is more convenient and we have the motivation to accomplish the task."

It is clear that students find it more convenient and easy to edit their work through clicking a few buttons. The additional function of Google Sites in translation also motivates students to accomplish the task.

\section{Conclusion and Teaching Implication}

The basic advantage of peer correction is that it will give students extensive practice in developing skills necessary for editing and revising their papers before they reach their final destination (Witbeck, 1976, p 322). In general, the students enjoyed using the wiki as it helped them to experience improvements in English writing and peer-to-peer interaction. It also facilitates them to work better as a team through the convenience of Google Sites. With the role of a peer reviewer, it is noticed that students do read and write more in English. By reading and leaving comments, peer learning and peer teaching is fostered among all students regardless of the extent, which shows that collaborative writing on Google Sites is not only beneficial to high achievers but all students. Moreover, students' comments can serve as an additional avenue for the teacher to diagnose students' understanding.

But several questions are left to be answered. Shown by Appendix (H), L1 was used by the students in online discussions to express some difficult concepts like indentation of paragraphs. Despite the benefits of 
maximizing students' chances to use English as the medium of communication, it is commonly agreed that people express their ideas better in their mother-tongues. Whether L1 or L2 should be used in the interaction among students needs further research in the future.

To conclude, as Engstrom \& Jewett (2005) suggested, the effectiveness of wiki application in learning and teaching depends on "careful planning and training of both students and instructors to familiarize them with the technology" (as cited in Woo et al, 2011). Obviously, a systematic approach with a comprehensive plan which familiarize students and teachers with the use of Google Sites is of utmost importance to the successful integration of web-based collaborative writing into the curriculum. The passion of both stakeholders can popularize the trend further more in the future.

\section{References}

Alexander, B. (2006). Web 2.0 - a new wave of innovation in teaching-learning. Retrieved from http://net.educause.edu/ir/library/pdf/ERM0621.pdf

Lo, J., \& Hyland, F. (2007). Enhancing students' engagement and motivation in writing: The caseof primary students in Hong Kong. Journal of Second Language Writing, 16, 219-237.

Goldberg, A., Russell, M., \& Cook, A. (2003). The effect of computers on student writing: A meta-analysis of studies from 1992 to 2002. The Journal of Technology, Learning, and Assessment, 2(1), retrieved December 10, 2010, from, http://escholarship.bc.edu/jtla/vol2/1/. 
Hossain, M., Aydin, H. (2011). A Web 2.0-based collaborative model for multicultural education, Multicultural Education \& Technology Journal, 5(2), 116 - 128

Nicol, D., Littlejohn, A., \& Grierson, H. (2005). The importance of structuring information and resources within shared workspaces during collaborative design learning. Open Learning, 20(1), 31-49.

Richardson, W. (2006). Blogs, wikis, podcasts and other powerful Web tools for classrooms. Thousand Oaks, CA: Corwin Press.

Sze, P. (2010). Online Collaborative Writing Using Wikis. Retrieved from http://iteslj.org/Techniques/Sze-Wikis.html

Trentin, G. (2009). Using a Wiki to Evaluate Individual Contribution to Collaborative Learning Project. Journal of Computer Assisted Learning, 25, 43-55.

White, R. \& Arndt, V. (1991). Process writing. London: Longman.

Witbeck, C. (1976). Peer Correction Procedures for Intermediate and Advanced ESL Composition Lessons. TESOL Quaterly, 10(3), pp. 321-326. Retrieved from http://www.jstor.org/stable/3585709

Woo, M., Chu, S., Ho, A., \& Li, X. (2011). Using a Wiki to Scaffold Primary-School Students' Collaborative Writing. Educational Technology \& Society, 14 (1), 43-54.

Woo, M., Chu, S., Ho, A., \& Li, X. (2009). Collaborative Writing with a Wiki in a Primary Five English Classroom. Proceedings of the 2009 International Conference on Knowledge Management [CD-ROM]. Hong Kong, Dec 3-4, 2009.

Zhu, C., Valcke, M., Schellens, T. (2009). A Cross-cultural Study of Online Collaborative Learning. Multicultural Education \& Technology Journal, 3(1), pp. $33-4$ 


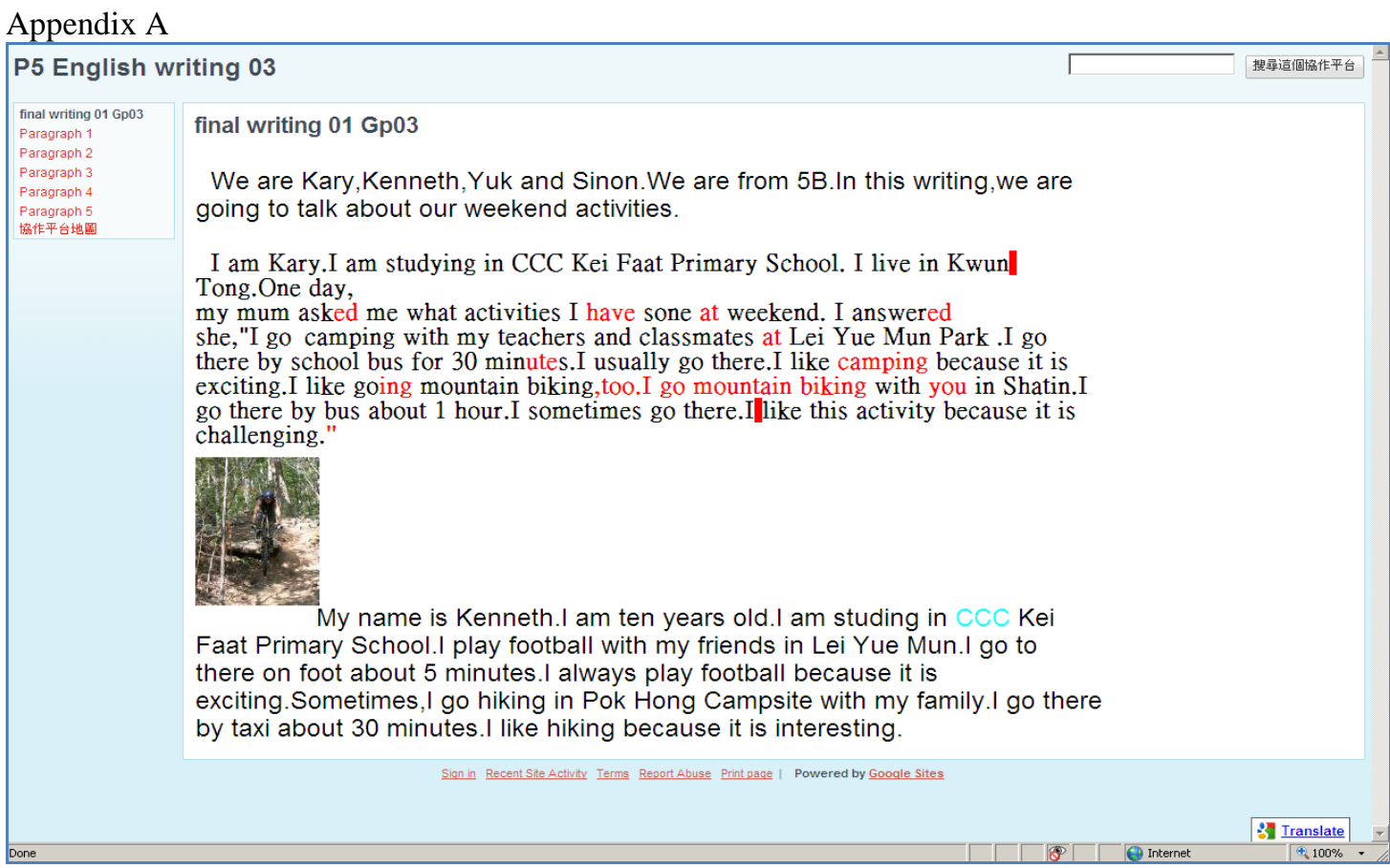

Appendix B 


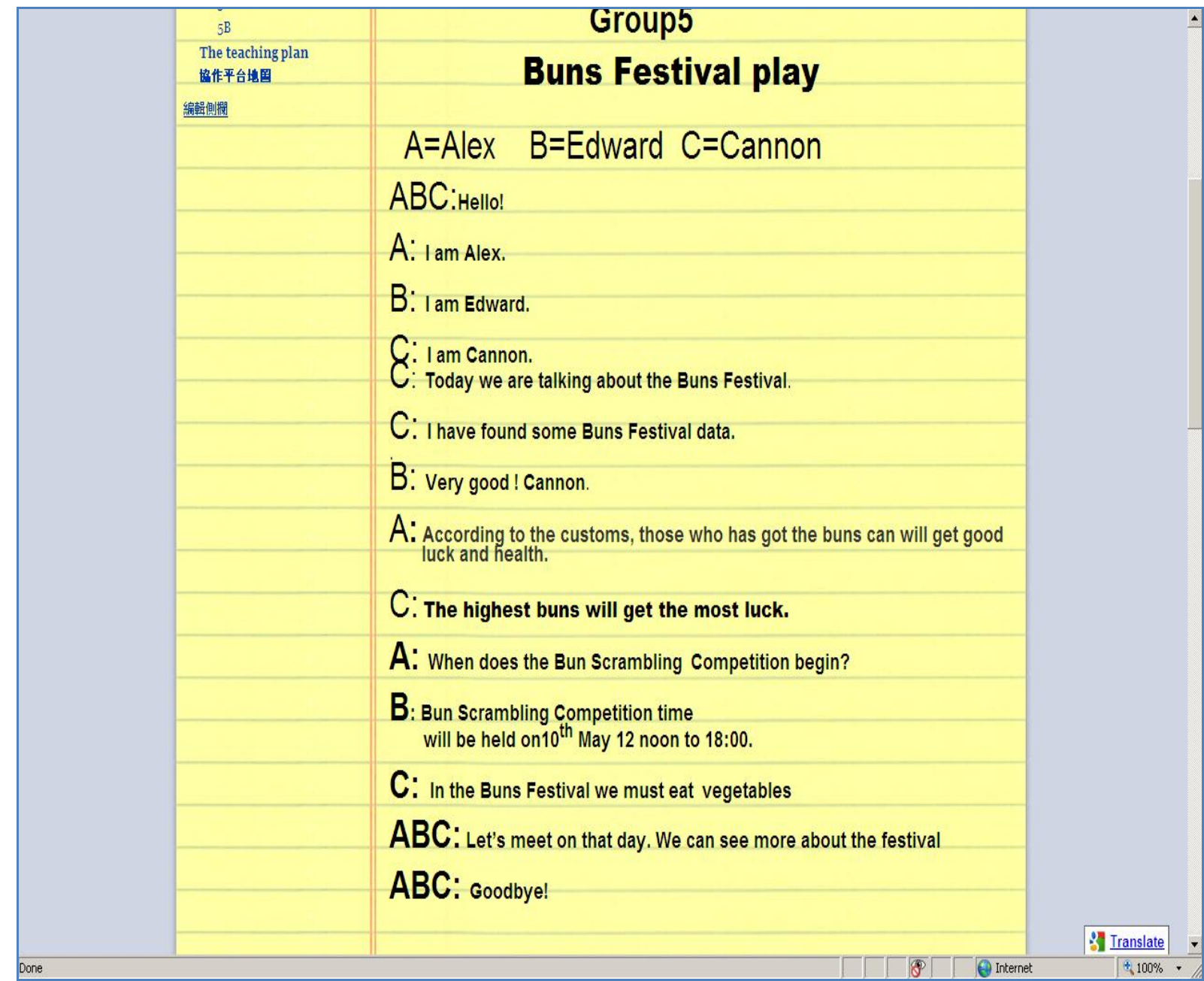

Appendix C 


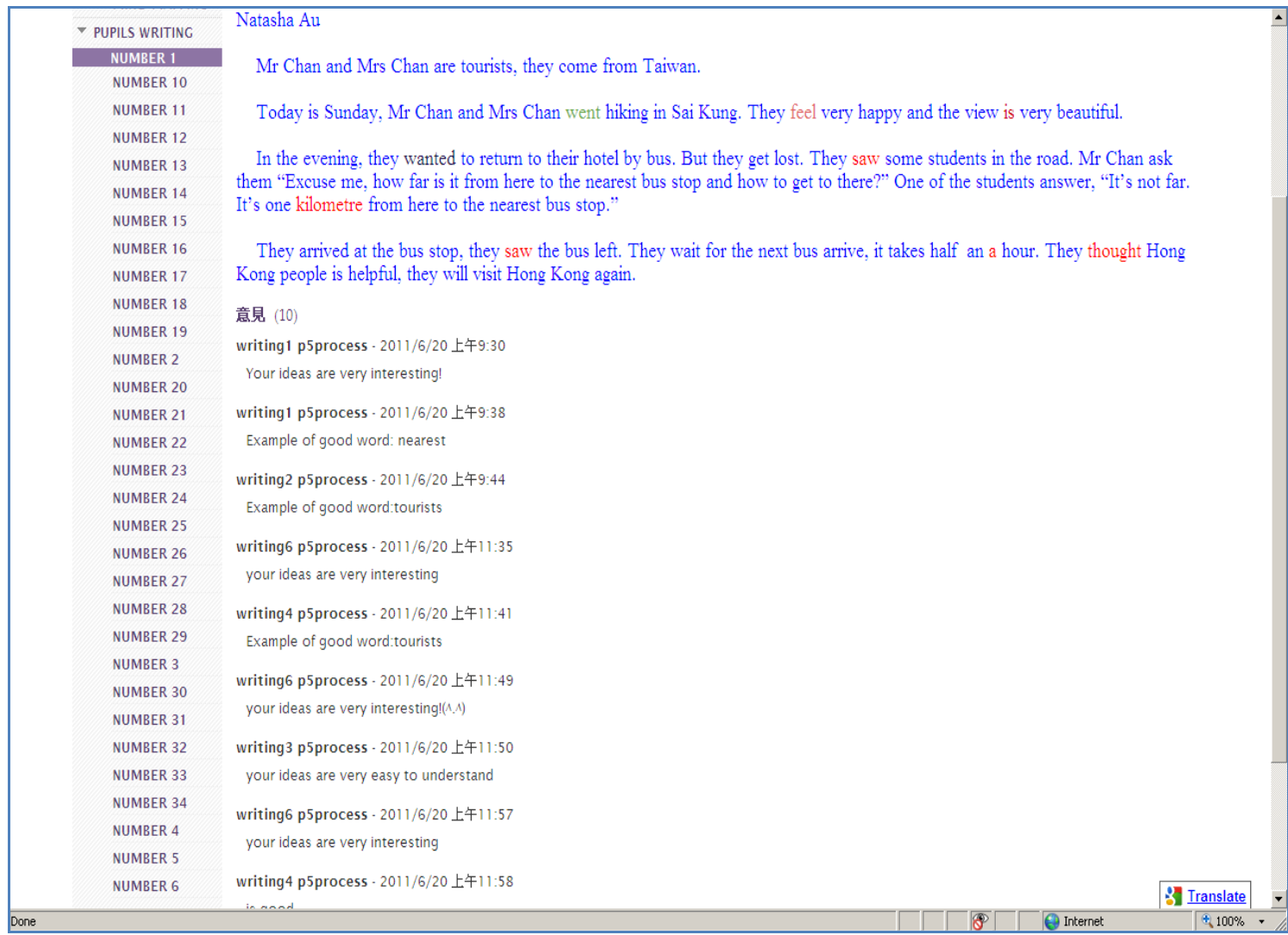

\section{Appendix D}

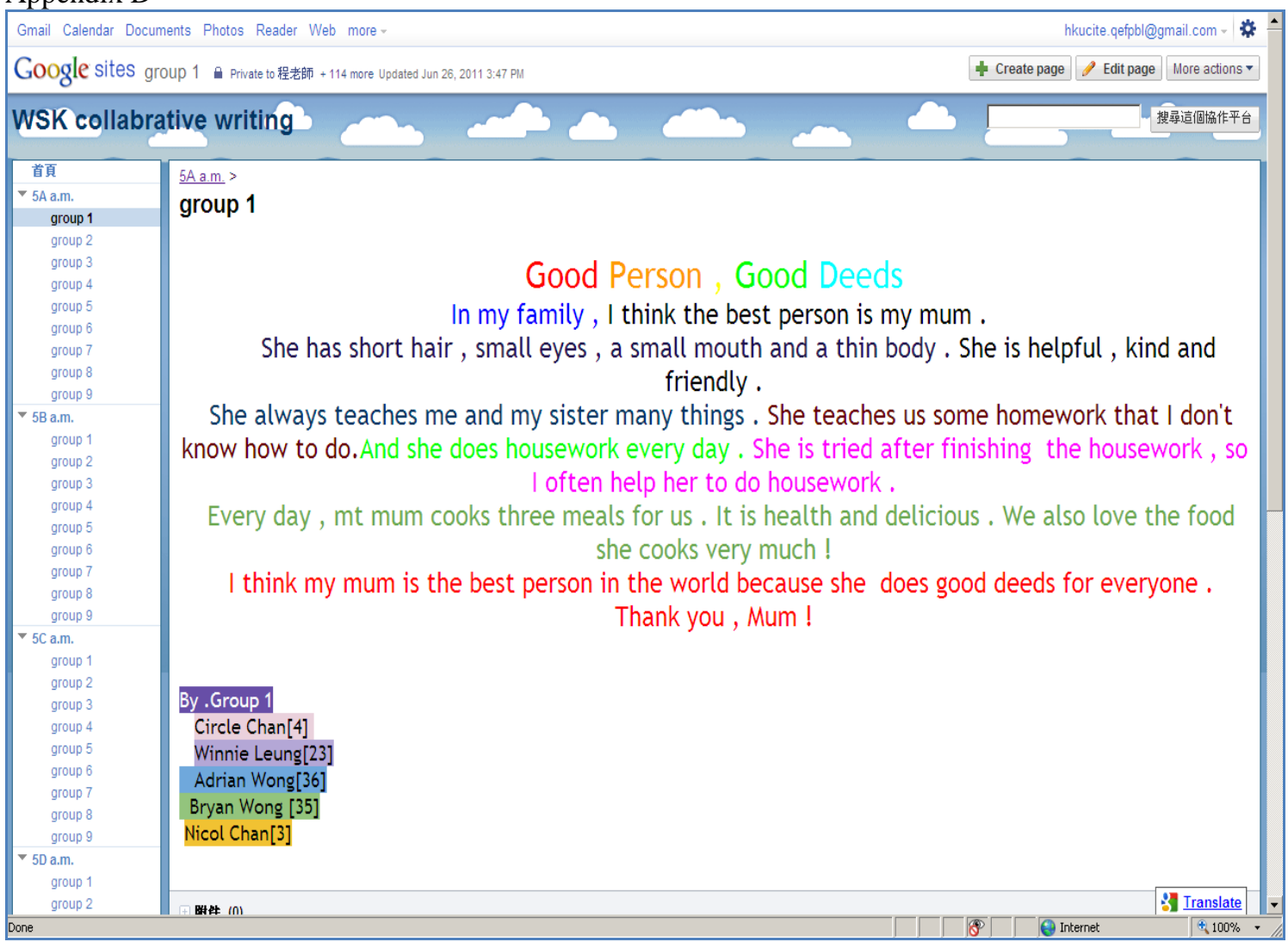

\section{Appendix E}




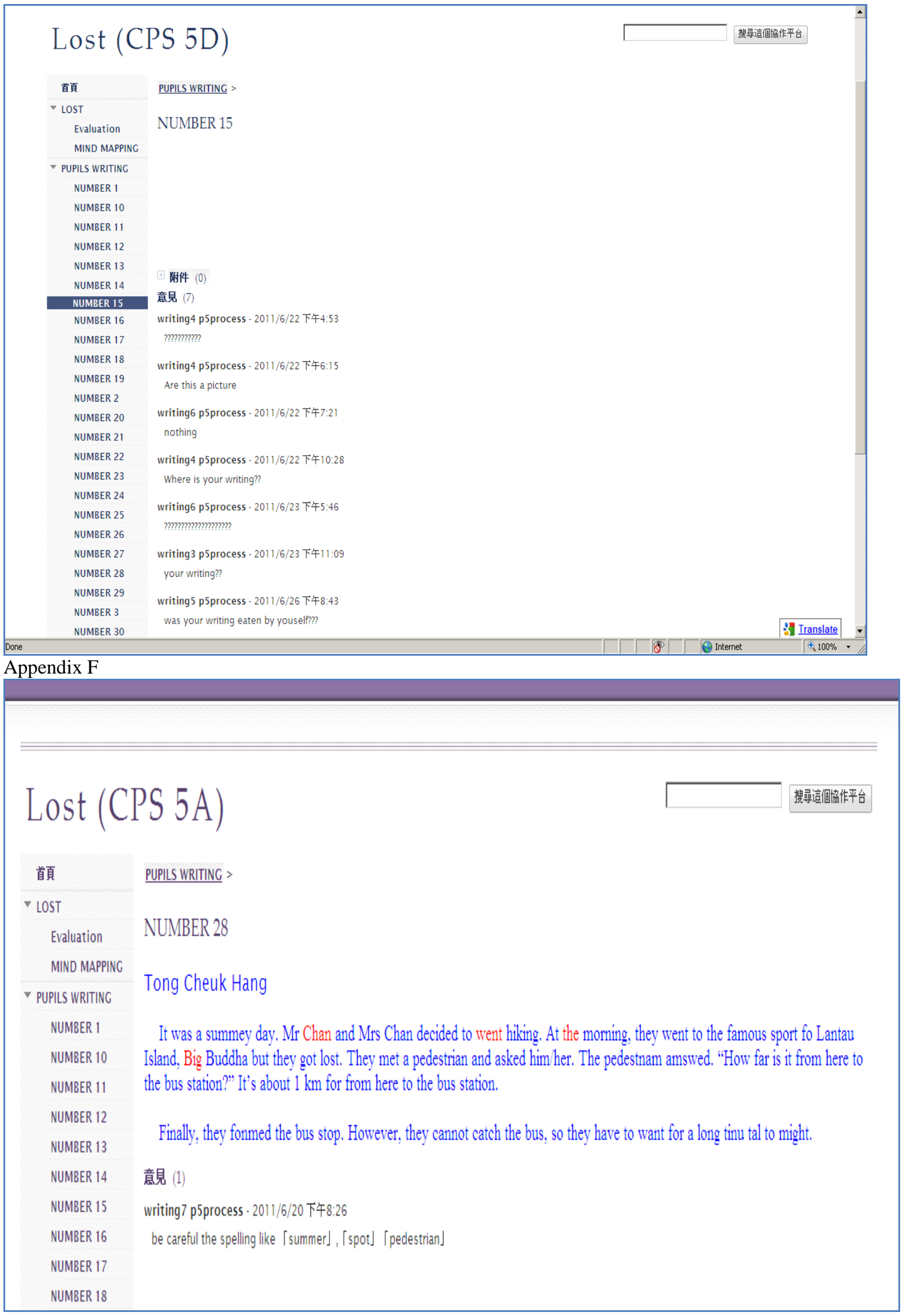

Appendix G

I:ISam-research \QEF|PublicationslConference paper of CITERS 2011\Experimenting with English collaborative writing 


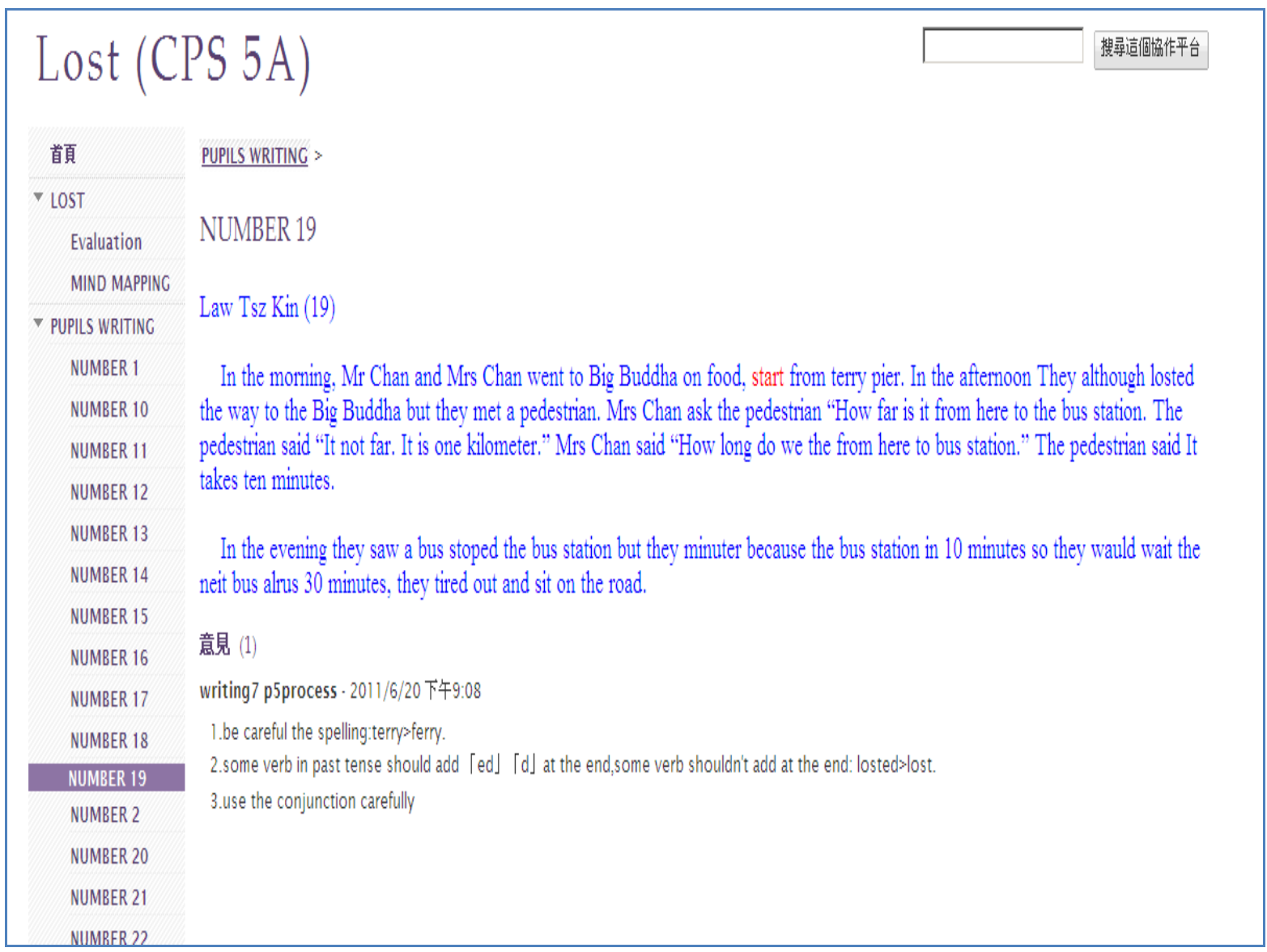

Appendix $\mathrm{H}$

writing 03

\section{Paragraph 5}

I am Simon. I am studying in CCC Kei Faat Primary School. I live in Kwun Tor with my mum because she likes doing archery, too. Mum and I sometimes doin Yue Mun Park. I like do archery because it is exciting. Also, I like going mountail take a bus to go there about 1 hour. I usually go mountain biking with my family mountain biking because it is challenging.

意見 (5)

張箬晴 $-2011 / 4 / 7$ 下午11:46

line 2 the word "Kwan" is wrong,you should write "Kwun".line 3 the word "from" is wrong you should say "in".

you should add the word to between "a bus" and "go".(line 5)

line 5 the word " $a$ " is wrong,you should say "about or for"

you are missing the word "biking" between "mountain" and "because".

陳司跣 $-2011 / 4 / 13$ 下午 $12: 32$

thak you

Yuk Lam Chan - 2011/4/13 下午12:35

Your writting is very interesting!

Yuk Chan

hong tik ho - 2011/4/13 下午12:36

開頭要有空格

砟希晴 $-2011 / 5 / 4$ 下午11:01

第三行 "I sometimes doing..... l like do" 應該係 "I sometimes do...... like doing" 改野果陣要小心!!!

Sign in Recent Site Activity Terms Report Abuse Print page I Powered by Google Sites

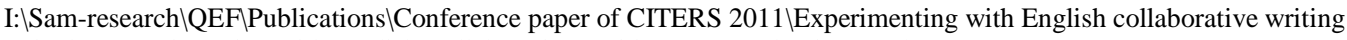

